\title{
La solidaridad imposible: Economía y naturaleza egoísta del ser humano
}

\author{
Andrés Monares \\ Universidad de Chile, Santiago, Chile. \\ Email: amonares@ing.uchile.cl
}

\begin{abstract}
Resumen $^{1}$ : La disciplina económica moderna dominante supone una naturaleza egoísta o maximizadora de la humanidad. Este fundamento, aunque hoy expresado en lenguaje "técnico", tiene su origen en la filosofía moral ilustrada y específicamente en el trabajo del moralista escocés Adam Smith. Como era evidente en su época, el autor asumía la maldad inherente de la especie humana dado el pecado original y la dirección providencial de los individuos por medio de esa maldad. Estos supuestos metafísicos condicionaron el desarrollo posterior de la Economía y su rechazo a la solidaridad. En tal sentido, a pesar de ignorarse en general esos fundamentos, la visión económica moderna mantiene su énfasis en el egoísmo cual motor de la conducta humana y, por ende, lo infructuoso e irreal que sería proponer sistemas basados en la solidaridad. No obstante, otras disciplinas socioculturales, junto con demostrar la falsedad del supuesto egoísta, han contribuido asimismo a remarcar la importancia de las instituciones socioeconómicas en los diversos sistemas de sustento. Lo que, a su vez, implica reconocer las influencias culturales en la ética económica; sea esta egoísta o solidaria.
\end{abstract}

Palabras claves: Solidaridad, egoísmo, ciencia económica, economía social y solidaria, instituciones económicas.

\section{Impossible solidarity: Economy and human beings' natural egoism}

\begin{abstract}
Modern dominant economic discipline presumes a maximizing egotistical human nature. These fundamentals, although expressed in technical terms today, have their origin in moral philosophy, and specifically in the work of the Scottish moralist Adam Smith. As was evident at the time, the author presumed the human species inherent Evil given the Original Sin and the providential direction of individuals due to this Evil. These metaphysical assumptions conditioned the further development of the discipline and its rejection of solidarity. In this regard, in spite of the overall ignorance of these assumptions, modern economic vision emphasizes egotism as the motor of human behavior, and thus finds the proposition of systems based on solidarity futile and unrealistic. However, other sociocultural disciplines, in addition to demonstrating the falseness of the egotistical assumption have contributed to stress the importance of socio-economic institutions in the various sustainability systems. This in turn, signifies the recognition of the cultural influences on the ethics of economics; be them egotism or solidarity.
\end{abstract}


Keywords: Solidarity, egoism, economic science, social and solidarity economy, economic institutions.

\section{A solidariedade impossível: Economia e natureza egoísta do ser humano}

Resumo; A disciplina económica moderna dominante supõe uma natureza egoísta ou maximizadora da humanidade. Este fundamento, ainda que expressado atualmente na linguagem “técnica”, tem seu origem na filosofia moral ilustrada e especificamente no trabalho do moralista escocês Adam Smith. Como era evidente na sua época, o autor assumia a maldade inerente da espécie humana dado o pecado original e a direção providencial dos indivíduos por meio dessa maldade. Estes supostos metafísicos condicionaram o desenvolvimento posterior da Economia e sua rejeição à solidariedade. Em tal sentido, a pesar de ignorar-se em geral esses fundamentos, a visão económica moderna mantem sua ênfase no egoísmo como motor da conduta humana e, por tanto, o infrutuoso e irreal que seria propor sistemas baseados na solidariedade. Não obstante, outras disciplinas socioculturais, junto com demostrar a falsidade do suposto egoísta, tem contribuído assim mesmo para remarcar a importância das instituições socioeconómicas nos diversos sistemas que lhe dão sustento. O que, por sua vez, implica reconhecer as influencias culturais na ética económica; seja esta egoísta ou solidaria.

Palavras-chave: a solidariedade, o egoísmo, economia social e solidária, as instituições econômicas

$* * *$

“Existe ya una extensa e imponente línea de economistas, desde Adam Smith hasta el presente, que han tratado de demostrar que una economía descentralizada, motivada por el egoísmo y guiada por las señales de los

precios, sería compatible con una disposición coherente de recursos económicos que pudiera considerarse, en un sentido bien definido, como superior a la gran clase de disposiciones disponibles” (Arrow \& Hahn, citados en Sen 1986: 178-179).

\section{Presentación}

La cita que encabeza este texto da cuenta, de manera asépticamente académica, del supuesto básico de la Economía Moderna: el ser humano es naturalmente egoísta. Lo que en jerga técnica se expresa en el modelo de los individuos maximizadores o guiados por una "racionalidad económica". Esa supuesta condición inherente da lugar a un sistema ad hoc: el mercado autorregulado. No obstante, los propios Kenneth Arrow y Frank Hahn (Sen, 1986) se cuestionan respecto de tal proposición que "ha sido planteada y sostenida con gran seriedad” por clásicos y neoclásicos, junto a buena parte de aquellos que se dicen economistas “científicos” y asumen consciente o inconscientemente esa expresión matematizada del Liberalismo. 
Para Arrow y Hahn — como para muchos economistas heterodoxos que evitan la costumbre ortodoxa de no cuestionarse-, es importante saber "no sólo si es cierta, sino si podría ser cierta" (cursivas del original) esa esencia humana egoísta o maximizadora.

Como cualquier estudiante de Economía puede testificar, esa singular proposición "planteada y sostenida con gran seriedad", es la base de todo el saber económico oficial. No hay curso de la materia que no comience con alguna forma de aceptación del egoísmo humano; obviamente, en términos “técnicos”. Principio que no necesitaría comprobación. Según los fundamentalistas por lo evidente de su veracidad; y según los pragmáticos, porque la verdad es un asunto secundario cuando se toma en cuenta la utilidad del modelo.

Sin embargo las serias y documentadas objeciones socioeconómicas y sociopolíticas, la inmensa cantidad de datos empíricos históricos y antropológicos acumulados, los cuantiosos resultados experimentales o la incapacidad explicativa de la doctrina dominante en diversas áreas, el egoísmo sigue en pie expresado en forma de maximización individual de utilidades. Sobrevive a las pruebas y ataques, reafirmando su lugar de piedra fundacional de la Economía: disciplina que se convierte en la "ciencia" sociocultural omnicomprensiva por excelencia.

Por ende, desde la economía ortodoxa las discusiones acerca de unas economías llamadas solidarias o sociales, no pasan de ser anecdóticas. Son terreno ignoto para la ciencia, la matemática y la seriedad académica. Pero, el punto es que más allá del ensimismamiento o autismo de esa Economía con pretensiones de "ciencia", a través de todo el mundo millones de personas viven su cotidianidad fuera de los estrictos pre-juicios de la ortodoxia. Esos millones han existido y existen por más que esas teorías no los vean, no los entiendan y pretendan dar cuenta de lo que en realidad esas personas quieren y hacen.

En ese escenario, para comprender los fundamentos y lógica del supuesto básico de la economía neoliberal, se recorrerá aquí un camino hacia el pasado y de vuelta. Primero, se hará una somera exposición del punto de vista ortodoxo a través de Friedrich von Hayek. En segundo lugar, se expondrán los orígenes metafísicos de la Economía dominante en Adam Smith; y luego, la "depuración” empirista de su obra que realizaron sus continuadores clásicos. Finalmente, se presentarán perspectivas que pueden cooperar a una mejor comprensión de las formas de sustento o economías sociales y/o solidarias.

\section{El progreso como “escape” de la solidaridad ${ }^{2}$}

Para exponer el cuadro oficial de la Economía Moderna y su elevación del egoísmo a inexorable y benéfico motor socioeconómico de la especie, se acudirá aquí a Friedrich Hayek, premio Nobel de Economía 1974 y 
uno de los ideólogos más destacados del Neoliberalismo. Se expondrán sus aseveraciones sobre la existencia de un orden social espontáneo. Lo cual complementa el autor con su visión de una razón limitada, de la naturaleza emocional de la moral y de la necesidad de autonomía individual. Todo ello le sirve para sustentar su rechazo a la solidaridad y a la justicia social, y afirmar la conveniencia del egoísmo.

Hayek (1982) reconoce que el Liberalismo descubre un orden socioeconómico "espontáneo”, gracias al cual se conforma la "sociedad extendida” u occidental moderna. Este tipo de colectividad “está basada en un proceso autorregulador”, el "mecanismo impersonal” del mercado, en el cual no se puede identificar ningún “propósito común”. Luego, afirma que el mercado autorregulado se impondría no sólo por ser natural, sino por su evidente conveniencia para la suma de individuos que conforman la "sociedad extendida”. De ahí su conclusión acerca de lo "lógico” o del todo evidente que es "intentar crear las condiciones bajo las cuales será sumamente probable que un individuo, tomado el azar, alcance sus fines en forma tan efectiva como le sea posible” (Hayek, 1993: 11). Tales condiciones son las que estructuran el "orden social liberal”, con su sistema de mercado autorregulado u “orden espontáneo”:

"El concepto central del liberalismo es que bajo la vigencia de reglas universales de conducta justa, que protejan un dominio privado de los individuos que pueda ser reconocido, se formará por sí mismo un orden espontáneo de las actividades humanas de mucho mayor complejidad del que jamás podría producirse mediante un ordenamiento deliberado” (Hayek, 1982: 182).

El que ese “orden espontáneo” no fuera “creado para un fin particular”, está lejos de ser un problema. Muy por el contrario. Es tal el beneficio general de tal orden autogenerado en los asuntos sociales, que vale la pena más allá de que "no pueda predecirse cuáles serán los objetivos particulares favorecidos y cuáles no” (Hayek, 1993). Y, en consecuencia, saber quiénes serán favorecidos por aquel orden y quiénes serán desfavorecidos por él. Este carácter indefinido es lo que justamente ha permitido el desarrollo de un sistema que sostiene a millones de personas. Es más, la existencia de pobres en las sociedades de mercado es un claro indicador del éxito y la superioridad del modelo. Aunque en desmedrada situación, desde la Revolución Industrial a la fecha, aquellos tendrían un nivel de vida incomparablemente mejor al de cualquier otra época: “el capitalismo creó al proletariado” y la "economía de mercado hizo posible que la gente sobreviviera; de otra forma, esa gente no hubiese sobrevivido” (Hayek, 1981: 76). ${ }^{3}$

Ese “orden espontáneo” a que da lugar el mercado autorregulado, o que es dicho mercado autorregulado, supera la capacidad del entendimiento humano (Hayek, 1981). La "estructura autorreguladora” sobrepasa “ampliamente el conocimiento de cualquier individuo", es "un orden que excede significativamente nuestra visión”. Así, al ser infructuoso cualquier intento de organización político-racional (en sentido greco-medieval), la so- 
ciedad deberá dejarse librada a la emocional "racionalidad económica” o al egoísmo lucrativo ${ }^{4}$. Un intento de planificación tan sólo interferiría el orden “espontáneo” paramal. Sería una quimera pensar en la posibilidad de "construir un mejor sistema de sociedad” a partir de una planificación y/o acuerdos políticos fundados en la razón.

Para respaldar su propuesta de un orden espontáneo, Hayek (1981) supone una singular evolución sociocultural unilineal de la humanidad... la cual entiende universal a pesar de referirse sólo a Occidente. Evolución que también sería moral y de ahí su referencia a "instintos morales" y "sentimientos espontáneos". Presume el autor que antes (no se sabe dónde ni cuándo), la vida de las bandas cazadoras-recolectoras y de las tribus se desenvolvía cara a cara, con un objetivo común y en base al altruismo. Es más, fue "durante este largo período, que precedió al desarrollo de lo que llamamos civilización, que el hombre adquirió sus respuestas genéticas, emocionales, sus sentimientos” (Hayek, 1981: 71-72). En especial se adquirieron dos actitudes necesarias en un grupo pequeño, pero "que no encajan bien en la sociedad extendida”: "el sentimiento del altruismo y el sentimiento de búsqueda conjunta tras metas comunes". ${ }^{5}$

La "sociedad extendida" —o la occidental moderna masiva, industrializada y de mercado- requiere el olvido de tales emociones morales primitivas. ${ }^{6}$ El mantenimiento del “orden espontáneo" hace imprescindible que no se intervenga la autonomía individual, el egoísmo o el individualismo. Se requiere su protección, pues la primitiva moral altruista imposibilitaría la conformación de la "sociedad extendida” o la destruiría. No ha de olvidarse, afirma Hayek, que "Todos los nuevos desarrollos se deben a la difusión de lo que podemos llamar 'individualismo’ o ‘escape’ de algunos individuos a esta obligación de compartir los métodos tradicionales” (Hayek, 1981: 74). O sea, el progreso se desata cuando las personas se liberan de las trabas altruistas y se comportan de manera egoísta o individualista.En otras palabras, el progreso "exigió la represión gradual de estos dos instintos básicos de altruismo y solidaridad” (Hayek, 1981: 72). ${ }^{7}$

La conclusión de la muy particular lógica de Hayek (1982), es que debe rechazarse la más nefasta supervivencia de la moral primitiva: la "justicia social" o "justicia redistributiva" ${ }^{8}$ Sería un concepto imposible de sostener argumentalmente, pues "no se han encontrado, ni se pueden encontrar pruebas o criterios mediante los cuales puedan fijarse dichas reglas” de justicia. Esa moral primitiva se expresaría hoy en la demagogia socialista, justificación de lo que es en realidad la verdadera injusticia social. Es más, por esa falacia que es la justicia social "el orden de derecho liberal se va destruyendo progresivamente”, ya que las reglas que se dicen justas "tendrían que ser determinadas por el arbitrio de la voluntad de los detentadores del poder": asegurar tal distribución "justa” implicaría transformar el "orden espontáneo del mercado (...) en un orden totalitario” (Hayek, 1982: 193). ${ }^{9}$

Lo injusto para Hayek es un contubernio de intereses particulares que atenten contra la autonomía individual, en su expresión de iniciativa 
productivo-comercial. Por tanto, tal confabulación es una amenaza a la esencia de una "sociedad liberal”. Lo que debería resolverse espontáneamente en función de las capacidades y suerte de cada cual, es reemplazado por la imposición de los intereses de los grupos de presión de las democracias representativas. ${ }^{10}$ Lo antaño autorregulado al modo de un sistema natural - una cuestión científica, objetiva y neutral como la órbita de los planetas-, se convierte en político. Será un tiránico orden arbitrario que busca una distribución más “igualitaria”, lo cual sólo lograría que se tengan menos cosas para distribuir: "La ilusión de que tenemos un producto social, que está a nuestra disposición para distribuirlo como queramos, es justamente eso: pura ilusión” (Hayek, 1981: 80). ${ }^{11}$

La sublimación del individualismo y de sus efectos autorreguladores en el marco del "orden espontáneo" del mercado, conlleva finalmente una sublimación del egoísmo. Cada cual al perseguir su propio interés velará de forma inconsciente - pero de manera eficiente- por el interés general. Se llegó al contrasentido de aceptar los beneficios del egoísmo; o lo que en la práctica es lo mismo, de negar la validez de cualquier principio ético que justifique intervenir contra el egoísmo. Como el ropaje científico da para justificar cualquier cosa, se liberó la sed de lucro individual de toda intervención externa o no económica. La actividad productivo-comercial implica servir "a propósitos recíprocos pero no comunes". Sin embargo, en el "orden del mercado" el concepto de "reciprocidad" se entiende desde el individualismo; sería "la reconciliación de propósitos diferentes para el beneficio mutuo de los participantes” (Hayek, 1982:183)

"Su lucha egoísta por las ganancias lo lleva a actuar así y le permite hacer, precisamente, lo que debería realizar para mejorar lo más posible las oportunidades de cualquier miembro de su sociedad, elegido al azar, pero sólo si los precios que puede obtener son determinados exclusivamente por las fuerzas del mercado y no por los poderes coercitivos del gobierno" (Hayek, 1989: 187). ${ }^{12}$

\section{El egoísmo natural}

Hoy los economistas ortodoxos explican las conductas humanas en base al modelo del "individualismo metodológico", es decir, al cálculo maximizador de sujetos aislados. De tal modo, "todas las instituciones, pautas de comportamiento y procesos sociales pueden ser explicados, en principio, en términos de los individuos únicamente" (Hirschman, 1978: 24). ${ }^{13}$ Mas, dicho enfoque no surgió de la nada en el siglo XX; tiene su historia y sus fundamentos. Ideas que son anteriores a las exposiciones de Lionel Robbins en el siglo XX o del pionero trabajo de Carl Menger en el XIX sobre la elección en un contexto de insuficiencia de medios (Polanyi, 1994).

El punto es que desde las posturas tecnocráticas se desconoce que se está ante una operacionalización de una ideología. Por lo cual se termi- 
nan invisibilizando sus orígenes, bases teóricas y los condicionamientos que aquella ideología dejó establecidos para las ideas e instituciones desarrolladas a partir de tal cimiento. De hecho, cuando Hayek habla de orden social espontáneo, limitación de la razón, moral emocional de carácter egoísta y necesidad de autonomía individual, está parafraseando (sin citar) a Adam Smith. Tal como ocurrió entre los coetáneos del filósofo moral escocés, Hayek también asume que aquel logró develar la verdadera naturaleza humana:

"Debido a que se ha hecho costumbre ridiculizar a Smith y a sus contemporáneos por su psicología supuestamente errónea, quizá podría aventurar mi opinión: pienso que para todos los efectos prácticos aún se puede aprender mucho más sobre el comportamiento de los hombres en La Riqueza de las Naciones que en la mayoría de los más pretenciosos tratados modernos sobre 'psicología social' " (Hayek: 1986a:11).

A pesar del reconocimiento que el Nobel austriaco le rinde al moralista escocés, soslaya los verdaderos fundamentos y fines de su ética religiosa. Lo traiciona al secularizarlo y dejarlo convertido en un irreconocible “científico”. ${ }^{14}$ Para nadie debería ser un misterio que el origen del hoy llamado "individualismo metodológico", hunde sus raíces en el trabajo de Adam Smith en pleno siglo XVIII. Mas, en todo caso, el pensador escocés es el gran sintetizador de una tradición; no inventó de la nada. Él es la cúspide de una cultura cuya expresión intelectual dominante fundió la interpretación de Juan Calvino del Cristianismo y el desarrollo de esos dogmas por los ilustrados ingleses del siglo XVII. En específico, los tópicos centrales de ese complejo de ideas reformadas-ilustradas, son la continua dirección divina del mundo por la Providencia y la irremediable maldad humana por el pecado original (Monares, 2012b).

Adam Smith (1723-1790) es reconocido a la fecha por ser el "padre” de la Economía, disciplina que habría sido fundada a partir de "La riqueza de las naciones”(1776). Libro donde expone un sistema “espontáneo” basado en una singular y para nada empírica antropología. Ante la consensual creencia europea occidental en una manifiesta naturaleza humana viciosa, los intelectuales ilustrados venían proponiendo diversas formas en que Dios guiaría a la humanidad usando precisamente esa corrupción innata. Ese gobierno divino explicaría la supervivencia de la especie, por medio de una forzosa e inconsciente cooperación, en un mundo de individuos degenerados. Smith expone una de las tantas posibles explicaciones surgidas de ese marco general. ${ }^{15}$

El autor de "La riqueza de las naciones" asume la necesidad inexorable de cooperación para mantener a la sociedad y, por su intermedio, al género humano en su conjunto. Mas, asimismo expone un problema básico:

“el hombre (...) en vano puede esperarla sólo de su benevolencia”. Dada la maldad inherente, la cooperación se “conseguirá con mayor 
seguridad interesando en su favor el egoísmo de los otros y haciéndoles ver que es ventajoso para ellos hacer lo que les pide”. Para que los demás realicen las acciones que sirvan a la propia conveniencia, debe invocarse su "propio interés": no "sus sentimientos humanitarios sino su egoísmo” (Smith, 2000: 17).

De hecho, la característica de la especie humana sería su "propensión a permutar, cambiar y negociar una cosa por otra”. La que es el medio por el cual "El hombre subviene a la mayor parte de sus necesidades" y “vive así, gracias al cambio”. En consecuencia, es “en cierto modo [un] mercader”. Luego, una sociedad compuesta por sujetos con tales características, "prospera hasta ser lo que realmente es, una sociedad comercial" (Smith, 2000: 24). El comercio sostiene a la humanidad; pero no como actos de reciprocidad altruistas ni de cooperación consciente. Lo que Smith expone y resuelve cuando habla de la "mano invisible":

“Ninguno se propone, por lo general, promover el interés público, ni sabe hasta qué punto lo promueve. Cuando prefiere la actividad económica de su país a la extranjera, únicamente considera su seguridad y cuando dirige la primera de tal forma que su producto represente el mayor valor posible, sólo piensa en su ganancia propia; pero en éste como en otros muchos casos es conducido por una mano invisible a promover un fin que no entraba en sus intenciones. Mas no implica mal alguno para la sociedad que tal fin no entre a formar parte de sus propósitos, pues al perseguir su propio interés, promueve el de la sociedad de una manera más efectiva que si esto entrara en sus designios” (Smith, 2000: 402).

En realidad, el filósofo escocés sólo aplicó al sistema productivocomercial sus ideas fundamentales que había expuesto antes en su obra capital: "La teoría de los sentimientos morales” (1759). En dicho texto expuso que los “sentimientos morales” son medios providenciales que dirigen a los individuos a cooperar con otros y a mantener a la especie de modo inconsciente... iy hasta contra su voluntad! El ejemplo que propone es que la "mano invisible" conduce a los "ricos" a distribuir su riqueza con quienes no tienen un patrimonio; y a pesar de su "natural egoísmo y avaricia”, y de que “sólo buscan su propia conveniencia”, la Providencia-mano invisible hace que los "pocos patrones señoriales” dividan "con los pobres el fruto de todas sus propiedades". De modo que "sin pretenderlo, sin saberlo, promueven el interés de la sociedad y aportan medios para la multiplicación de la especie” (Smith, 1997: 333).

En consecuencia, de esa descripción de una realidad divinamente determinada es que toma lógica y fuerza la propuesta de un orden espontáneo. El gobierno providencial de la sociedad, que utiliza los sentimientos, no debe ser intervenido: Dios logra lo que la maldad humana no querría, y lo que la corrupta razón es incapaz de planificar y conseguir. Se eleva así la no intervención a principio supremo de la sociedad de mercado y a la condición necesaria del mercado autorregulado. La autonomía individual pasa a 
ser el valor principal de la tradición reformada-ilustrada o de lo que llegaría a conocerse como Modernidad. ${ }^{16}$

La solidaridad no sólo es imposible; si se quisiera poner en práctica lograría metas diferentes y hasta contrarias a las deseadas por la Deidad. Sin embargo, no hay problema en ese egoísmo ciego. Pues al ser un medio providencial, finalmente promoverá el interés “de la sociedad de una manera más efectiva que si esto entrara en sus designios”. Por ende, lejos de traer riqueza o progreso, la solidaridad provocaría sus contrarios: pobreza y retraso. Si bien Smith jamás hubiera aceptado que la maldad, envidia, avaricia o la codicia eran sentimientos virtuosos; sencillamente sufe lo impulsaba a creer que dichos vicios eran los únicos medios que Dios tenía a mano para dirigir a la corrupta humanidad hacia sus benéficos objetivos. ${ }^{17}$

Es importante recordar que la estructura de pensamiento general de Smith, donde se ubica su afirmación de una naturaleza egoísta del género humano en particular, no es para nada novedosa. El vicio cual factor explicativo de la conducta individual se enmarca dentro de la tradición europea occidental pos Reforma Protestante. Y en esos términos tuvo sus predecesores y sus continuadores. A estos últimos es importante entenderlos como seguidores del moralista, al tiempo que miembros de la misma tradición.

Bajo ese último entendido, se considerará primero al utilitarista británico Jeremy Bentham (1748-1832), a quien se tiene aquí por una especie de nexo entre Smith y la Economía posterior que pretende asumir el estatus de “ciencia” al modo de la Física. En “La psicología del hombre económico” el autor presenta sin tapujos ni eufemismos (morales o "técnicos”) la tradición ya expuesta acerca del egoísmo de la especie: "el yo lo es todo, comparado con el cual, las demás personas, agregadas a todas las cosas juntas, no valen nada” (Bentham, 1978: 12. Cursivas del original). Como para el pensador utilitarista “el predominio general de la propia estimación sobre cualquiera otra clase de consideración, queda demostrado” en la realidad, la organización económica derivada de aquella jamás podría ser solidaria, altruista o responder a cualquier otra virtud. Ello sería una cuestión evidente, pues se manifiesta de manera empírica:

“Deberá dependerse siempre del principio de acción cuya influencia sea la más poderosa, constante, uniforme, permanente y más generalizada entre la humanidad. Ese principio es el interés personal; el sistema de economía que se construya sobre cualquier otra base, se edifica sobre una base falsa” (Bentham, 1978: 13).

El egoísmo de los individuos que se juega en el terreno de los sentimientos de "placer" y "dolor" — buscando el primero y evitando el segundo-_, es una tendencia moral tan regular que podrá ser medida. Es posible encontrar un resultado o "valor" moral de la comparación de "todos los placeres por una parte, y los de todos los dolores por otra”. Si el resultado "se inclina hacia el lado del placer, señalará una buena tendencia del acto en 
su totalidad, respecto a los intereses de la persona individual” (Bentham, 1978: 16. Cursivas del original).

Esa perspectiva de “difundir el método experimental de razonamiento de la rama física a la moral” y, por ende a la Economía, Bentham la señala en su "Filosofía de la ciencia económica" como el rol de "Newton" en lo moral... altísimo título que se otorga a sí mismo. ${ }^{18}$ Entonces, concluirá el autor que es el "dinero el instrumento para estimar la cantidad de dolor o placer”; sin él se debe decir "adiós a la política y la moral”. Corolario al cual Bentham no podría haber llegado, sin el imprescindible supuesto de una tendencia egoísta natural ligada a los sentimientos y por ello regular. ${ }^{19}$

En la misma línea general, por más que puedan identificarse diferencias en lo particular, se ubica el clérigo inglés Robert Malthus (1766-1834). En su preocupación por la explosión demográfica en relación a la disposición de alimento, su postura es acorde a la de Smith: la Providencia guía a los humanos por medio del “instinto”. El “gran Autor de la naturaleza (...) el Creador (...) ha prescrito a cada hombre que persiga, como su objeto primario, su propia seguridad y dicha, y la seguridad y la dicha de aquellos inmediatamente conectados con él” (Malthus, 1998: 544).

En otras palabras, el interés propio, amor propio o egoísmo (valgan las diferencias singulares del mismo mecanismo providencial-natural) dirige a los individuos a un bien superior que, racional y solidariamente, no podrían conseguir. Es más, el ser humano fracasaría si pretendiera obtener de modo consciente "la felicidad general", siguiendo como principio la "benevolencia”. Con mayor razón cuando se habla del bajo pueblo: "los más ignorantes se ven conducidos a promover la felicidad general, fin que ellos jamás se hubieran propuesto si el móvil principal de su conducta hubiera sido la benevolencia” (Malthus, 1998: 544). De ahí que el autor se oponga a la caridad y a los subsidios a los pobres: la solución a la pobreza no es a través de medidas políticas. Es natural, providencial o autorregulada... con todas las penurias que ello implica para las clases bajas. Por extraño que parezca, esa vía natural es una prueba de la infinita bondad y sabiduría divina.

El reverendo Malthus sería la última expresión completamente religiosa de lo económico; algo así como un ilustrado tardío. Mas, ello no fue obstáculo para que tuviera un fructífero diálogo intelectual y una profunda amistad con David Ricardo (1772-1823). ${ }^{20}$ La condición laica de este millonario especulador y economista “científico” — tal como ocurrió en el caso de Bentham—-, no le impidió continuar también con la tradición del egoísmo y el sistema automático. ${ }^{21}$

Ricardo expone cómo la ambición de ganancias da lugar a lo que hoy se llama ajuste automático: el "deseo continuo por parte de los capitalistas de abandonar un negocio poco provechoso por otro más ventajoso”. En lo puntual, se refiere a las "clases adineradas" que "viven del interés que les produce el dinero”: “banqueros” e industriales solicitantes de préstamos. 
El “capital circulante” permite al industrial, frente a las fluctuaciones de la oferta y la demanda, adecuarse espontáneamente a la situación: “despide algunos de sus trabajadores y reduce o anula su demanda de dinero a los banqueros y capitalistas” (Monares, 2008). Como se puede constatar, aunque con un lenguaje más técnico, Ricardo mantiene la preponderancia del egoísmo, el interés personal, los deseos de maximizar o de lo que se llegó a llamar la "racionalidad económica”. Precisamente, ello da lugar a un equilibrio automático.

Esa búsqueda de lucro es la que permite el dinamismo y la falta de planificación de la actividad económica en un contexto de mercado autorregulado. Sólo se requiere un marco legal que establezca reglas generales de convivencia productivo-comercial. La solidaridad no cumple rol alguno en el individualista, competitivo y automático mundo de los negocios. Además, por qué un millonario como Ricardo y sus colegas podrían haber considerado necesaria la solidaridad, más allá de los buenos modales comerciales entre gentlemen. Incluso por una cuestión de estatus en una sociedad extremadamente jerarquizada: sería indecoroso para personas de tal nivel.

No se seguirá más adelante en esta somera exposición del camino recorrido por el principio del egoísmo en Europa Occidental. ${ }^{22}$ El lector avisado divisará en el horizonte el marginalismo, al Robinson Crusoe neoclásico, a las “expectativas racionales” de la "nueva macroeconomía clásica” y, finalmente, la vuelta al punto dónde comenzó este apartado, el “individualismo metodológico”. Y a pesar de que el voluntarismo de Eric Roll —como muestra del voluntarismo economicista contemporáneo-, sostenga la liberación de la Economía de “sus antecedentes filosóficos” y el triunfo del "utilitarismo, en su sentido estrictamente pragmático”, es evidente que ello sólo es un deseo o una mala interpretación “científica”. ${ }^{23}$

Por más que se quiera asumir la postura cientificista, y pueda ser ella considerada hasta respetable, la historia de la Economía Moderna quedó condicionada por sus orígenes. Lo cual sucede por más que se ignoren esos comienzos, se recurra a otros conceptos o se elaboren nuevos y se disfracen las viejas lógicas con ropaje secular y técnico. O sea, lejos de liberarse la Economía sigue encadenada a "sus antecedentes filosóficos” y “al carácter providencial del orden natural” (Roll 2003). La religión y filosofía de Adam Smith, ese piadoso moralista del siglo XVIII, siguen siendo los inconmovibles cimientos de la ortodoxia contemporánea. Puede verse entonces que esta vez sí acierta Roll cuando señala un vicio (anti)intelectual de los economistas: "la tradicional resistencia a ahondar demasiado profundamente en los aspectos más filosóficos”.

La rueda ideológica del Occidente Moderno gira y vuelve al origen... o nunca se movió de ese principio: del supuesto del egoísmo y, por tanto, de la imposible solidaridad. Todo indica, más allá de la brevedad de este texto, que el desarrollo de la Economía es más una versión remozada (y sobre todo amnésica) de la tradición reformada-ilustrada. Sólo se obvió a 
Dios y se lo reemplazó por la "naturaleza", por una condición inherente de la humanidad o por las preferencias que no pueden escapar de elegir en función del propio interés. El resto es ignorancia autocomplaciente y voluntarismo ciego:

"Ciertamente, es satisfactorio que esta disciplina, en sus versiones más recientes, aparezca más o menos emancipada de sus antecedentes filosóficos y se convierta, genuinamente, en una ciencia positiva, libre de supuestos implícitos de carácter normativo" (Roll, 2003: 567).

No obstante los deseos de Roll o de otros economistas "científicos", no es posible que ninguna disciplina escape a algún tipo de "supuestos implícitos [o explícitos] de carácter normativo”. Sostener esa separación es de hecho un supuesto normativo. Para decirlo en términos científicos: las demostraciones siempre responden a determinados axiomas... sépalo o no quien utiliza esas demostraciones y aunque pretenda que son "ciencia positiva”. No han existido, no existen ni existirán los dispositivos teóricometodológicos sin historia, autooriginados en el limbo de una supuesta técnica pura. Por ende, el problema no es que exista tal relación. Si bien parece académicamente inconveniente ignorar ese nexo, lo peor es la deshonestidad intelectual que esconde el innegable componente ideológico de la "ciencia positiva". ${ }^{24}$

\section{Ni ángeles, ni demonios: Sustento, cultura e instituciones}

Desde el punto de vista "académico", es importante reflexionar respecto de la falsedad de una naturaleza egoísta y acerca de la diversidad cultural humana. Pero, también son importantes, y tal vez mucho más, los aspectos sociopolíticos referidos a cómo se quiere vivir, en torno a qué principios éticos.

Para comenzar a desmentir una supuesta naturaleza egoísta de la especie, sepuede recurrir a la antropóloga Susan McKinnon. Ella remarca que esa visión, ligada al desarrollo del capitalismo occidental, ha "surgido en circunstancias históricas y culturales especiales que no son función de una lógica genética natural y universal”. ${ }^{25} \mathrm{El}$ evidente relativismo cultural que marca inexorablemente dichas concepciones, se deja de lado cuando de modo artificial y antojadizo se eleva el supuesto del egoísmo innato al estatus de "un universal transcultural". Lo cual es acompañado por un "rechazo fundamentalista de otras realidades humanas". Se universaliza o naturaliza una experiencia cultural e histórica específica, “que surgió bajo las condiciones históricas del capitalismo temprano y que sigue estando fundamentada hoy por los valores económicos neoliberales”(McKinnon, 2012: 73). 
Aunque existen otras culturas que reconocen el "comportamiento radicalmente automaximizador" al estilo del economicismo occidental moderno, el punto es que “con frecuencia lo llaman brujería”. Se considera que las personas que realizan este tipo de práctica "actúan para restringir sus relaciones sociales y acumular recursos para su propio interés personal" (McKinnon, 2012). De hecho, para la mayor parte de la humanidad el egoísmo es una cuestión "antinatural en el sentido normativo: se considera locura, brujería o base para el ostracismo, la ejecución o, como mínimo, la terapia” (Sahlins, 2011: 67).

Es más, se puede concluir que sostener al egoísmo como una conducta natural de los humanos es "unailusión de proporciones antropológicas a escala mundial”. En otras palabras, no resiste análisis. De hecho, un principio de relación social más universal o mucho más extendido en la historia, ha venido dado a través del parentesco (que en general se determina bajo criterios extra genéticos). De donde surge a su vez una ética singular: "los parientes deben sentir amor uno por el otro" y ayudarse mutuamente en todos los ámbitos de la vida; incluido por supuesto la esfera económica o de la búsqueda del sustento (Sahlins, 2011).

Considerando lo antedicho, la economicista descripción de la evolución humana de Hayek, hecha suya por los economistas científicos, ortodoxos o neoliberales, implica asumir fundamentosinsostenibles. ${ }^{26}$ La gran acumulación de datos en verdadempíricos de la Antropología, la Historia e incluso de la Historia Económica deberían ser suficientes. ${ }^{27}$ Además, la rigidez del dogmatismo ortodoxo es tal, que hasta es posible enfrentarlo desde un mínimo conocimiento sociocultural e histórico. Es del todo evidente que el ser humano no podría existir sin una herencia y vida colectivas. La existencia en grupo ha dependido de desarrollos y consensos racionales, los cuales se han guiado por la solidaridad y la búsqueda del bien común la mayor parte de la historia.

El egoísmo natural ha sido y es una utopía como factor organizativo de la vida en común. La ironía es que el individualismo y su promoción del egoísmo es una herencia colectiva; elaborado, difundido y enriquecido por una comunidad intelectual utilizando un legado cultural colectivo. Y, finalmente como se ve en Hayek, en no pocos casos conlleva un afán solidario y altruista (implícito o explícito) para con otros miembros de la sociedad y hasta para con anónimos de otras sociedades.

Superado el primero y en realidad más simple punto, es necesario revisar ahora la relación entre sistemas de sustento y solidaridad. Sería necesario aclarar una cuestión que pareciera una especie de sentido común o voluntarismo de algunas personas ligadas a los estudios o experiencias de economía social y solidaria. Puntualmente, la referencia es a que estas experiencias y las personas que las llevan a cabo, poseen una moral superior o asumen posturas políticas de resistencia. Al ser solidarias estarían al margen de las relaciones individualistas, competitivas y lucrativas al modo 
del mercado autorregulado (por más que en muchos casos esas personas entran y salen de contextos lucrativos de mercado). ${ }^{28}$

Se estima aquí que ignorar las condicionantes institucionales de los sistemas o prácticas de sustento, es tan erróneo como el voluntarismo de creer en el principio del egoísmo natural. Karl Polanyi (1994) y el enfoque institucional o sustantivo ayudan a desmitificar el que las economías sociales y solidarias dependen de la bondad de las personas, de la innata fraternidad de los grupos subalternos y/o marginados, como asimismo de una supuesta bondad inherente del ser humano en general.

El institucionalismo o sustantivismo ha expuesto la forma en que las prácticas y sistemas de sustento están incrustadas en las sociedades. O sea, el modo cómo se relaciona inseparablemente con otras partes de la cultura y surgen desde esos otros sectores de la cultura. No hay economía en sí misma, cual sistema aislado o autónomo. Por cierto que existen los sistemas de sustento, pero no son instituciones en sí y ante sí. Lo económico se materializa cuando otras instituciones noeconómicas necesitan de la producción, distribución o consumo de bienes materiales o servicios. Un caso típico y fácil de comprender son las fiestas religiosas o carnavales: los objetivos eminentemente místicos y sociales de tales eventos requieren de aspectos materiales para su realización y el buen cumplimiento de sus fines. Ello aclara la afirmación de Polanyi acerca de que la economía es "simplemente el resultado del funcionamiento de otras instituciones no económicas”:

“Como conclusión general se puede afirmar que la producción y distribución de bienes materiales estaba incrustada en las relaciones sociales de tipo no económico, de tal forma que ni existía un sistema económico institucionalmente separado ni una red de instituciones económicas. Ni el trabajo, ni la disponibilidad de objetos ni su distribución se llevaban a cabo por motivos económicos, es decir, ni por deseo de ganancia, ni por temor a pasar hambre individual” (Polanyi, 1994: 127).

Desde esa perspectiva, no tienen sentido los acercamientos a las economías no modernas, tribales o sociales y solidarias que rozan el mito del "buen salvaje” o del pobre intrínsecamente radical-fraternal. La solidaridad está integrada al sistema social y se expresa en lo económico. Es deber del pariente, del miembro de la etnia o de la comunidad, realizar ciertos actos (socio)económicos dentro de un marco de obligaciones -explícita o implícitamente- recíprocas. Ello ocurre más allá de la calidad moral de la persona en cuestión y por algo existen en muchos casos presiones o castigos institucionalmente determinados para quienes incumplan la norma. No todos quieren ser solidarios a todo evento.

Marshall Sahlins (1983) da cuenta de la materialización no siempre universalmente solidaria de la ética del parentesco. La pregunta en estos casos es con quién o quiénes debo/quiero ser solidario y hasta qué punto. 
Por ejemplo, “las retribuciones son sólo más o menos equivalentes, y más o menos inmediatas en el tiempo"; variación que está "notablemente correlacionada con la distancia del parentesco": "cuanto más cercano al hogar, el intercambio se vuelve más desinteresado”; y cuanto más alejado, al no existir obligación alguna, podríavolverse más interesado (Sahlins, 1983: 144-145). En otras palabras, la solidaridad entre parientes puede irse relajando a medida que los lazos son más lejanos y hasta puede desaparecer con los no parientes; al punto de ser moralmente aceptable el desinterés, el engaño, la agresión, el robo o incluso la esclavización y el asesinato.

Un caso contemporáneo de esa relajación de la solidaridad se da en el mundo andino y probablemente muchos blancos extranjeros la pueden haber experimentado en carne propia. Desde la perspectiva occidental esas actitudes se consideran formas de engaño o estafas; pero para los nativos andinos no contradice la sentencia "no seas ladrón", un pilar básico de su ética:

"Lo que rige para el grupo endógeno (ayllu), no necesariamente tiene validez para la universalidad inclusiva (todos los seres humanos) (...) Las normas vigentes dentro del ayllu no siempre son aplicadas (o no en el mismo sentido) a los foráneos (...) a un comunero del mismo ayllu, nunca le engañaría económicamente, pero sí lo puede hacer a un comerciante foráneo o un turista” (Estermann, 2006: 260,261 y 263). ${ }^{29}$

Claramente, en estos contextos el "amor desinteresado (agapé), como tal, no es un valor, y tampoco lo es la ayuda altruista”. Asimismo, la justicia como categoría no es "formal y universalmente homogénea”; dentro de la familia y el ayllu es diferente de la que rige con quienes no pertenecen a esos círculos (Estermann, 2006). Vistas así las cosas, el ideal de universalidad moral-legal occidental moderno no parece en este caso demonizable. Sobre todo en términos morales supone un deber solidario con cualquiera, sea cual sea su género, etnia, religión, edad, etc. Lo que pareciera una buena norma ética a fin de tener una buena vida colectiva. ${ }^{30}$

\section{Palabras finales}

Es necesario reflexionar acerca de los efectos del reduccionismo economicistay su supuesto del egoísmo natural, en el estudio y solución de asuntos socioculturales. Obviamente limita lo que se puede ver y las respuestas teórico-prácticas que se pueden emprender para abordar y solucionar diversos problemas. Además de que, como bien afirma McKinnon, su afán "encubiertamente prescriptivo" — generalmente disfrazado de "ciencia” o de saberes académicos_-, termina naturalizando y universalizando la tradición occidental moderna:

“Tal narrativa [del reduccionismo economicista] no sólo borra la tremenda evidencia histórica y contemporánea de la creatividad huma- 
na y la diversidad cultural en el mundo - y las verdades de otras realidades culturales - sino que también restringe gravemente la clase de preguntas que podemos plantear y los tipos de mundos sociales que podemos imaginar y tratar de crear para nosotros mismos” (McKinnon 2012: 154-155).

En el caso que aquí se ha tratado, al unificar a todo el género humano bajo los criterios de una tradición singular, se termina negando explícita o implícitamente la posibilidad de la solidaridad en la práctica. Pues, esa base teórica ha servido para justificar la implementación de sistemas socioeconómicos por ser supuestamente técnicos y neutrales. Esta situación, una vez develada, debería impulsar la tarea de desarrollar y materializar aspectos sociopolíticos referidos a cómo se quiere vivir, en torno a qué principios éticos. Pareciera difícil que la solidaridad sea dejada de lado por el egoísmo (el cual no debe confundirse con la iniciativa individual ni con la competencia).

Por otro lado, es necesario asumir que todas las culturas tienen sus luces y sombras. Ni todo lo étnico o popular/subalterno es bueno en sí, ni todo lo occidental moderno es intrínsecamente malo. En tal sentido, es un amplio campo de discusión el cómo materializar la solidaridad más allá del parentesco, lo étnico, la condición de clase, el género, la religión, etc. Se cree aquí que se abre un ámbito de trabajo teórico-práctico para buscar una síntesis entre una real universalidad de la justicia y la solidaridad en verdad igualitaria, y ciertas instituciones socioeconómicas no modernas; o de ciertos valores no modernos y ciertas instituciones occidentales modernas. Por supuesto que respetando las particularidades culturales de cada pueblo, los cuales deben ser activos agentes de esas posibles síntesis.

A todas luces debe superarse el reduccionismo economicista; obviedad que se dificulta con el dominio académico y político de la ortodoxia. Sin embargo, también es necesario cuidarse de no caer en otros espejismos que puedan parecer atractivos. Un ejemplo de ello son algunos tipos de imaginarios sociales y solidarios de carácter utópico o idealizado. Ya ha sido suficiente de imposiciones culturales foráneas en el Sur Global, para caer ahora en una fantasía endógena. Por más atractiva y benigna que parezca. 


\section{Notas}

${ }^{1}$ El presente texto corresponde a la ponencia presentada en el Seminario Internacional de Economía Social y Solidaria: "Más allá del Neoliberalismo”, 25 al 28 de mayo de 2015. Universidad Católica del Maule-Universidad Academia de Humanismo Cristiano-Universidad Central. Santiago-Talca.

2 En esta sección hemos adecuado el apartado "Mercado Autorregulado y Neoliberalismo” de Monares (2012a).

${ }^{3}$ No son pocas las dudas que despierta el recurrido argumento de que el capitalismo de mercado autorregulado es superior, pues permite la supervivencia de más personas que todos los sistemas socioeconómicos conocidos y citar a la Revolución Industrial como ejemplo. Empero, debe recordarse que dicho período de expansión económica sin parangón en Gran Bretaña, coincidió con una miserable condición de sus clases bajas al punto de impulsarlas a emigrar por miles (Hobsbawm 2010. Schnerb 1982).

${ }^{4}$ Es muy importante diferenciar la moderna "racionalidad económica" del concepto de "razón" en sentido greco-medieval, es decir, de la facultad que permite a la especie humana guiar libremente sus actos. Desde esta perspectiva, será la política racional la encargada de dirigir a la comunidad hacia el fin final: la felicidad (Monares 2012b).

${ }^{5}$ Susan McKinnon (2012) crítica la creencia de una fijación de respuestas psicológicas en la especie humana en el remoto Pleistoceno, las cuales se traducirían en instituciones socioculturales universales y aún vigentes.

${ }^{6}$ Para sopesar la fuerza del argumento, hay que recordar la carga valórica negativa que lo "primitivo" tiene desde el eurocentrismo en sí y desde sus expresiones modernistas y/o racistas.

${ }^{7}$ La extraña y eurocentrista reconstrucción de la evolución humana de Hayek, tiene su correlato en los procesos de modernización, es decir, en la imposición planificada de patrones socioculturales europeos y estadounidenses. Los desarrollistas proponen que deben eliminarse las "barreras" al "desarrollo": los patrones "tradicionales" o solidarios (Monares 2008).

${ }^{8}$ Como en un "orden de mercado" nadie hace "una distribución justa o injusta”, sería mejor hablar de "dispersión” de ingresos (Hayek 1982).

${ }^{9}$ La sublimación neoliberal de la libertad y el individualismo pueden comprenderse, y hasta compartirse, al considerar la experiencia totalitaria soviética y nazi. Pero Hayek (1995), como otros neoliberales, terminan viendo un Camino de servidumbre en todo sistema que no sea uno de mercado autorregulado. Lo cual no tiene lógica histórica ni política. Además, esa forma de ver la sociedad está cegada por y encerrada en la visión occidental que lleva cualquier argumento a su término lógico: es un todo o nada, donde se es (neo)liberal o totalitario.

10 James Buchanan (1982), economista neoliberal y Nobel de la especialidad 1986, distingue entre democracias "ilimitadas" y las "limitadas", para referirse respectivamente a sistemas políticos que no restringen el alcance de los gobiernos de aquellos que lo restringen. En su exposición, acorde a las ideas políticas de Hayek, rechaza las 
democracias por no "aplicar abiertamente limitaciones al radio de acción de la actividad gubernamental”. Por su parte, Milton Friedman (1980), premio Nobel de Economía 1976, también aboga por la no intervención, pues sus "efectos son precisamente lo contrario de los objetivos perseguidos por los reformadores”. El mercado autorregulado guiado por el egoísmo siempre será mejor y más eficiente que cualquier solución racional y/o planificada. Así por ejemplo, para Friedman un "supermercado" sería más democrático que la propia democracia al dar lugar a "una unidad sin sometimiento".

${ }^{11}$ El Neoliberalismo resolvió el problema de la redistribución a través del Estado subsidiario: ayudas para la ciudadanía que vive en la miseria, a fin de que así puedan elevarse a la condición de pobres. Se garantizaría así la igualdad de condiciones para que los antes miserables compitan por los recursos en el mercado con el resto de la población.

${ }^{12}$ Lionel Robbins, padre de la “ciencia económica”, se quejaba en 1935 de "la muy reiterada acusación de que la Economía supone un mundo de hombres a quienes sólo preocupa su propio interés”... punto de vista “estúpido y exasperante” para “todo buen economista" (Robbins, 1951: 132). De haber conocido los textos aquí citados de Hayek, un "buen economista" galardonado con el Nobel de la especialidad, tal vez no le hubiera agradecido sus "consejos y críticas” a la 2da. edición de su Ensayo sobre la naturaleza y significación de la ciencia económica. Se equivoca Robbins al sostener que quienes terminaron relacionando la Economía con el egoísmo fueron los críticos de "mentes adversas al esfuerzo que exige pensar con exactitud" o el "público profano" que "se ha dejado embaucar". Como bien señalan sus destacados colegas Arrow y Hahn al principio de este trabajo, la relación entre Economía y egoísmo "ha sido planteada y sostenida con gran seriedad” por una larga lista de distinguidos economistas.

${ }^{13}$ Hirschman, aunque cauto, defiende el "reduccionismo" del individualismo metodológico y, tal como Robbins, asegura que "la suposición de que los individuos son racionales [economizadores] y egoístas no forma parte de la doctrina”. La cual, según Hirschman, tampoco "asume que los individuos sean 'átomos' con una existencia presocial”.

${ }^{14}$ De entre los economistas de su época, Smith "sin duda, es el más grande, no sólo por su influencia sino por la comprensión y reconocimiento claro del problema central de la ciencia”: la autorregulación (Hayek, 1986b: 89).

${ }^{15}$ Considerando la visión religiosa reformada sólo como una entre tantas, Hirschman (1978) revisa la "insistencia categórica" europea en concebir a la humanidad como "realmente es" a partir del Renacimiento y Sahlins (2011) expone que la concepción de un ser humano malvado es una "ilusión” occidental que se puede rastrear desde la antigua Grecia.

${ }^{16}$ La filosofía occidental moderna y contemporánea asocia la autonomía a Immanuel Kant, entendiéndola cual fruto racional y profano de la Ilustración. Mas el pensador prusiano, igual que su contemporáneo Smith, cree que la Providencia emplea la maldad humana: recurre a la "insociable sociabilidad” o "antagonismo" para materializar su plan. Uno donde la especie sobrevive y progresa a través de la conformación de la sociedad política, que es el modo providencial de controlar la naturaleza viciosa de aquella (Monares, 2012b). 
${ }^{17}$ Aunque escapa al objeto de este trabajo, esa manifestación continua de la Providencia a través de los sentimientos permite concebir la acción humana como constante: la metafísica fundamenta el enfoque científico secular del fenómeno humano (Monares, 2008). Entre los muchos ejemplos citables, tómense en cuenta otros dos del siglo XVIII: “Así como el mundo físico está gobernado por las leyes del movimiento, el universo moral está gobernado por las leyes del interés" (Helvecio, citado por Hirschman 1978: 49-50); "La avaricia, o el deseo de ganancia, es una pasión universal que opera en todo tiempo, en todo lugar, y sobre todas las personas” (Hume, citado por Hirschman 1978: 61).

${ }^{18}$ Por más que Bentham reconozca a Helvecio como precursor de ese camino experimental en la moral. Para la postura de este último, ver nota 16.

${ }^{19}$ Esta conjunción entre moral y búsqueda de lucro no es nueva, estaría establecida en Inglaterra desde por lo menos fines del siglo XVII en la relación de las probabilidades, la búsqueda de una "certeza moral” y la limitación racional por el pecado original. En Francia, Condorcet habla de "matemática social” para analizar cómo "elegir de entre proposiciones probables y, sobre todo, en saber evaluar su grado de probabilidad”; y asimismo, define la "utilidad" del individuo como "todo lo que le procura placer o le evita algún dolor” y que los sujetos le otorgan un "valor” (Monares 2008).

20 "Esa amistad pasará a la Historia por haber dado origen a la correspondencia literaria más importante en el curso entero del desarrollo de la Economía Política” (Keynes 1997: 32).

${ }^{21}$ Eric Roll (2003) expone que ya Adam Smith y "sobre todo” Ricardo abandonan la metafísica: "el carácter providencial del orden natural puede decirse que sólo recibía culto de labios para afuera” (Roll 2003: 420). No hay nada que comentar en cuanto al craso error de Roll con Smith; mas en Ricardo, como en cualquier creyente en el orden espontáneo, es imposible que escapara de los fundamentos metafísicos... fuera o no consciente de ellos.

22 Otra forma de expresión europea occidental de la visión negativa de la humanidad, es el concepto exclusivo y excluyente de "fraternidad” en la Ilustración, la Revolución Francesa y la Modernidad (Monares, 2015).

${ }^{23}$ Lo que es oscuro para los economistas es clarísimo para el teólogo protestante Paul Tillich, quien explica cómo el gobierno providencial logra la "armonía”, el orden espontáneo, el ajuste automático o el equilibrio capitalista: “...a pesar de que cada uno puede estar motivado por el interés de la ganancia, a pesar de que cada uno quiere beneficiarse, al final se alcanzarán los objetivos generales de la producción y el consumo por alguna ley oculta [de Dios]. Esta misma idea subyace también, con muchos matices, en la teoría del capitalismo estadounidense moderno. Existe esta creencia básica en la armonía [providencial]” (Tillich, 1977: 355-356).

${ }^{24} \mathrm{Y}$ mucho peor es cuando se utiliza la supuesta neutralidad de la "ciencia” para legitimar políticas públicas o diversas medidas socioeconómicas de un profundo componente ideológico. Chile en dictadura y desde 1990 a la fecha, es un típico ejemplo de reformas estructurales neoliberales justificadas por ser "técnicas".

${ }^{25}$ McKinnon critica la Psicología evolutiva como vástago de la economía neoliberal, por eso su crítica es atingente a lo aquí expuesto. 
${ }^{26}$ Lo cual no debería ser algo nuevo para los propios economistas: John Maynard Keynes en El final del laissez-faire (1926) había sostenido la falacia de un modelo "que no se deduce de los hechos, sino de una hipótesis incompleta introducida en aras de la simplicidad". Pues, "la conclusión de que los individuos que actúan independientemente para su propio provecho producirán el mayor agregado de riqueza depende de una variedad de supuestos irreales”.

${ }^{27}$ Entre una extensa bibliografía, aparte de Sahlins (1983 y 2011) y de McKinnon (2012), se puede considerar a Polanyi (1994), Polanyi, Arensberg \& Pearson (1976), Godelier (1976) y Monares (2008 y 2014).

${ }^{28}$ El autor basa este tópico en su experiencia y en la de informantes ligados a la Economía social y solidaria; puntualmente, provenientes del campo religioso cristiano y/o con posturas políticas de izquierda. Albert Hirschman (1986) expone diversas experiencias latinoamericanas de "desarrollo popular" que contradicen tanto el principio individualista de la ortodoxia económica, como ciertos supuestos del campo de la Economía Social y Solidaria.

${ }^{29}$ El antropólogo Paul Bohannan (1996) cuenta una anécdota que expone las diferencias éticas entre los pueblos, en su caso entre los tiv de Nigeria y los occidentales modernos: uno de los nativos le contó que un hombre se ahogó en un río y ante la consulta de por qué no lo ayudó siendo un buen nadador, el tiv respondió que por no ser pariente. La ira e incomprensión del antropólogo fue similar a la que el mismo nativo sintió cuando el antropólogo le contó que no veía a su madre hace unos cinco años. La reflexión final de Bohannan es que años después seguro ambos siguen convencidos de la superioridad de sus propios valores.

${ }^{30}$ Se asume que tal ideal de universalidad moral-legal occidental moderno, se le pueden hacer muchas observaciones en el pasado y todavía. Pero, como efecto del propio imperialismo cultural, ha dado pie a que los mismos colonizados/dominados formulen sus críticas y plataformas políticas de liberación en términos occidentales modernos (Sartre, en Fanon, 2009). 


\section{Bibliografía}

Bentham, J. (1978), Escritos económicos, Fondo de Cultura Económica, México D.F.

Bohannan, P. (1996), Para raros, nosotros. Introducción a la Antropología Cultural, Akal Editor, Madrid.

Buchanan, J. (1982), “Democracia limitada o ilimitada”, en Estudios Públicos, Nro. 6. Centro de Estudios Públicos, Santiago

Estermann, J. (2006), Filosofía andina. Sabiduría indígena para un mundo nuevo, ISEAT, La Paz.

Fanon, F. (2009), Los condenados de la tierra, Fondo de Cultura Económica, Buenos Aires.

Friedman, M. \& Friedman, R. (1980), Libertad de elegir. Hacia un nuevo liberalismo económico, Ediciones Grijalbo, Barcelona.

Godelier, M. (Comp.), (1976), Antropología y economía, Editorial Anagrama, Barcelona.

Hayek, F. (1981), “Los fundamentos éticos de una sociedad libre”, en Estudios Públicos, Nro. 3, Centro de Estudios Públicos, Santiago.

Ídem, (1982), “Los principios de un orden social liberal”, en Estudios Públicos, Nro. 6, Centro de Estudios Públicos, Santiago.

Ídem, (1986a), “Individualismo: el verdadero y el falso” en Estudios Públicos, Nro. 22, Centro de Estudios Públicos, Santiago.

Ídem, (1986b), “El mensaje de Adam Smith en el lenguaje actual”, en Estudios Públicos, Nro. 23, Centro de Estudios Públicos, Santiago.

Ídem, (1989), “El atavismo de la justicia social”, en Estudios Públicos, Nro. 36, Centro de Estudios Públicos, Santiago.

Ídem, (1993), “La competencia como proceso de descubrimiento”, en Estudios Públicos, Nro. 50, Centro de Estudios Públicos, Santiago.

Ídem, (1995), Camino de servidumbre, 3ra. Reimpresión, Alianza Editorial, Madrid.

Hirschman, A. (1978), Las pasiones y los intereses. Argumentos a favor del capitalismo antes de su triunfo, Fondo de Cultura Económica, México D.F.

Ídem, (1986), El avance en colectividad. Experimentos populares en la América Latina. Fondo de Cultura Económica. México D.F. 
Hobsbawm, E. (2010), La era del capital, 1848-1875, Crítica, Buenos Aires.

Keynes, J. (1926), El final del laissez-faire, en:, visitada el 18 de mayo de 2015.

Ídem, (1997), "Robert Malthus (1766-1834). El primer economista de Cambridge”, en Primer ensayo sobre la población, R. Malthus, Ediciones Altaya, Barcelona.

Malthus, R. (1998), Ensayo sobre el principio de la población, Fondo de Cultura Económica, México D.F.

McKinnon, S. (2012), Genética neoliberal: mitos y moralejas de la psicología evolucionista, Fondo de Cultura Económica, México D.F.

Monares, A. (2008), Oikonomía. Economía moderna. Economías, Editorial Ayún, Santiago.

Ídem, (2012a), “Una breve historia del libre mercado: Teología reformada, filosofía moral y ciencia económica”, en Hacia otras economías. Críticas al paradigma dominante, H. Richards \& R. González (compiladores), Grupo Repensar la Economía, Santiago.

Ídem, (2012b), Reforma e Ilustración. Los teólogos que construyeron la Modernidad, Editorial Ayún, Santiago.

Ídem, (2014), De la Economía Moderna a una comprensión socioeconómica de los sistemas de sustento, América Latina en Movimiento. Ecuador, en: , visitada 3 de mayo de 2015.

Ídem, (2015), “Ni pecadores, ni pobres, ni razas inferiores: La limitada fraternidad ilustrada y moderna”, en Revista Cultura y Religión, Volumen 8, Nro. 3 (en preparación), Universidad Arturo Prat.

Polanyi, K. (1994), El sustento del hombre, Mondadori, Madrid.

Polanyi, K.; Arensberg, C. \& Pearson, H. (1976), Comercio y mercado en los imperios antiguos, Editorial Labor, Barcelona.

Robbins, L. (1951), Ensayo sobre la naturaleza y significación de la ciencia económica, Fondo de Cultura Económica, México D.F.

Roll, E. (2003), Historia de las doctrinas económicas, Fondo de Cultura Económica, México D.F.

Sahlins, M. (2011), La ilusión occidental de la naturaleza humana, Fondo de Cultura Económica, México D.F. 
Ídem, (2000), Investigación sobre la naturaleza y causas de la riqueza de las naciones, Fondo de Cultura Económica, México D.F.

Ídem, (1983), Economía de la Edad de Piedra, Akal Editor, Madrid.

Schnerb, R. (1982), El siglo XIX. El apogeo de la expansión europea (18151914), Ediciones Destino, Barcelona.

Sen, A. (1986), “Los tontos racionales. Una crítica de los fundamentos conductistas de la teoría económica”, en, F. Hanh \& M. Hollis (comp.), Filosofía y Teoría económica, Fondo de Cultura Económica, México D.F.

Smith, A. (1997), La teoría de los sentimientos morales, Alianza Editorial, Madrid.

Tillich, P. (1977), Pensamiento cristiano en Occidente. Segunda parte: De la Ilustración a nuestros días, Editorial La Aurora, Buenos Aires.

Recibido: 18.06 .15

Aceptado: 28.01.16 